\title{
Pancreatic exocrine enzyme deficiency associated with asphyxiating thoracic dystrophy ${ }^{\star}$
}

\author{
MANOUCHEHR KARJOO, C. EVERETT KOOP, DAVID CORNFELD, and \\ PHILIP G. HOLTZAPPLE
}

From the Division of Gastroenterology and Surgery, The Children's Hospital of Philadelphia; and the Department of

Pediatrics of the University of Pennsylvania School of Medicine, Philadelphia, Pennsylvania, U.S.A.

\begin{abstract}
Karjoo, M., Koop, C. E., Cornfeld, D., and Holtzapple, P. G. (1973). Archives of Disease in Childhood, 48, 143. Pancreatic exocrine enzyme deficiency associated with asphyxiating thoracic dystrophy. Asphyxiating thoracic dystrophy, a constrictive thoracic chondrodystrophy present at birth, is associated with tachypnoea, recurrent pulmonary infections, and failure to thrive. In our patient, a successful surgical procedure for the alleviation of the thoracic constriction resulted in improvement of ventilatory function and reduction in the frequency of respiratory infections, but did not improve the growth rate. Further investigation disclosed chronic diarrhoea, steatorrhoea, and neutropenia with impaired pancreatic zymogen secretion, suggesting the presence of a second congenital abnormality. The association of exocrine pancreatic insufficiency with asphyxiating thoracic dystrophy has not been previously described.
\end{abstract}

Asphyxiating thoracic dystrophy, a familial chondrodystrophy, presents in the neonatal period with a thin, narrowed, elongated chest. This restrictive thoracic disease causes tachypnoea and repeated pulmonary infections. During the first months of life the respiratory difficulties retard growth and are responsible for the high incidence of infant deaths (Barnes, Hull, and Symons, 1969; Hanissian, Riggs, and Thomas, 1967; Herdman and Langer, 1968; Jeune, Beraud, and Carron, 1955; Pirnar and Neuhauser, 1966). The existence of normal lungs at necropsy has suggested that surgical attempts designed to enlarge the chest cavity would benefit the affected patients (Barnes et al., 1971; Durand et al., 1965).

We are presenting a boy with asphyxiating thoracic dystrophy in whom surgical correction was performed with alleviation of the respiratory difficulties. The growth failure persisted and investigation disclosed chronic exocrine pancreatic insufficiency in addition to the chondrodystrophy.

\section{Case reports}

Case 1. A 3-month-old white boy was admitted for evaluation of failure to thrive. He was a product

Received 2 June 1972.

^Supported in part by C.R.C. Grant Number RR 240. P.G.H. is recipient of Career Research Development Award 1-KO4-HD 70026. of a term pregnancy of a gravida IV, para II, 28-year-old mother, and weighed $2.32 \mathrm{~kg}$ at birth. On examination in the nursery he was found to have an abnormally narrow chest, but was free of respiratory distress during the first week of life. After discharge from hospital there was a gradual increase in difficulty with respiration, and failure to gain weight. In addition, his bowel movements were described as loose and foul-smelling. The parents were not related, there was no history of chest deformities, early infant deaths, or malabsorption in the family.

At 3 months of age he weighed $3.8 \mathrm{~kg}$ and was 43 $\mathrm{cm}$ in length (below the 3 rd centile for his age); head circumference was at the 25th centile. Nevertheless, he was active and alert, but slightly hypotonic. Though the respiratory rate was 60 to 80 per minute, there was no evidence of respiratory distress or heart failure. His chest was small and narrow, with good breath sounds. The heart was normal. He had a protuberant abdomen and both liver and spleen were palpable $3 \mathrm{~cm}$ below the costal margins. The extremities were normal. There were no abnormal neurological findings.

Clinical studies. Laboratory studies included normal urinalysis, stool culture, blood sugar, serum proteins, calcium, phosphorus, alkaline phosphatase, electrolytes, and BUN. The CBC was haematocrit 37, $\mathrm{Hb} 12 \cdot 3$, WBC 8600 with $16 \%$ neutrophils, $77 \%$ lymphocytes, $6 \%$ monocytes, and $1 \%$ basophils. PBI was $8.5 \mu \mathrm{g} / 100 \mathrm{ml}$. Blood gases in room air were $p \mathrm{H} 7 \cdot 37, \mathrm{PCO}_{2} 39$, and $\mathrm{Po}_{2} 55$. Urinary $\mathrm{FeCl}_{3}$ 


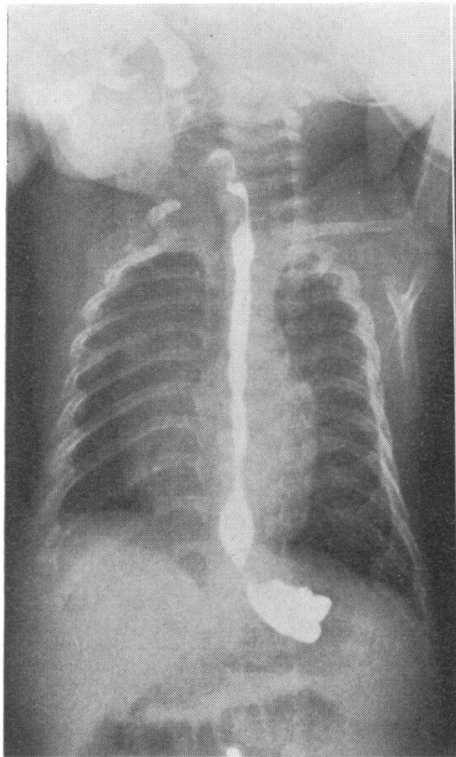

Fig. $1(a)$

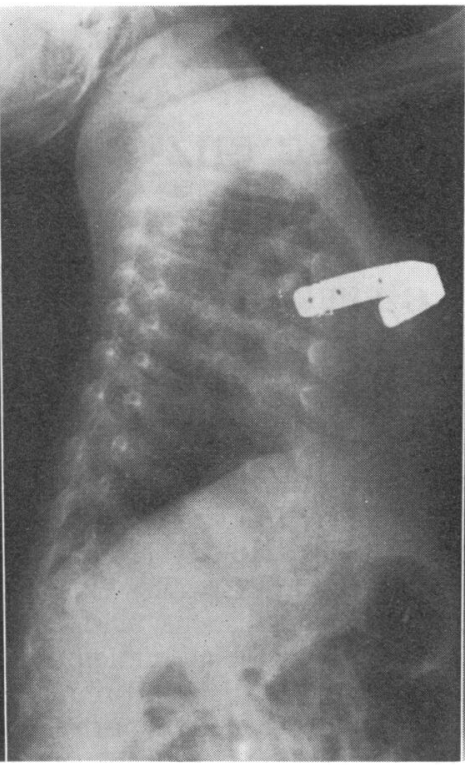

Fig. $1(b)$

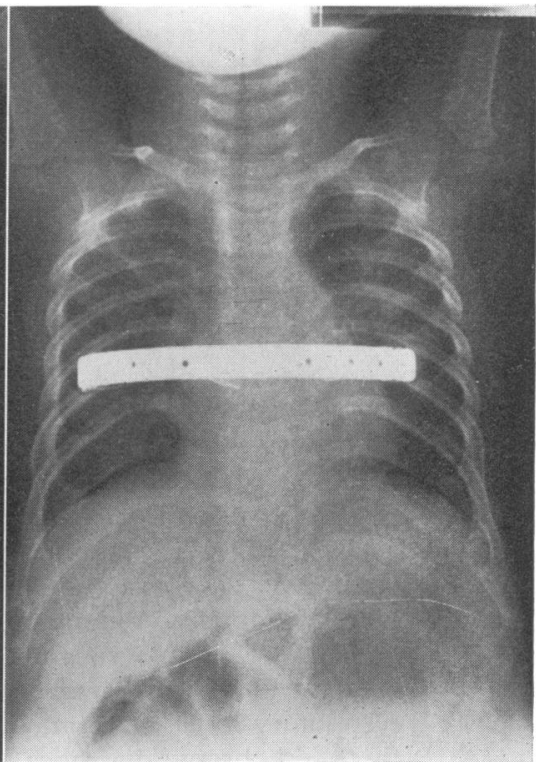

Fig. $1(c)$

FIG. 1.-Chest $\mathrm{x}$-ray at 8 months of age before surgery $(a) ; \mathrm{x}$-rays $(b)$ and $(c)$ show expansion of the thoracic cage after thoracic reconstruction with tar in place.

test was negative. An elongated narrow chest with short longitudinal ribs was seen on chest $x$-ray. The anterior ends of the ribs were flared. The heart and pulmonary vasculature were normal. While the lung fields were clear, there was a suggestion of hypoaeration consistent with the reduced thoracic volume. A bone survey did not disclose any other abnormalities. The appearance of the thorax was considered characteristic of the chondrodystrophic syndrome, asphyxiating thoracic dystrophy.

Failure to thrive was initially ascribed to the respiratory effort related to this syndrome. During the succeeding 7 months he gradually became more tachypnoeic, especially after eating. Repeated pulmonary infections and failure to gain weight became more clinically significant. Cyanosis never developed. Because of progressive pulmonary difficulties and respiratory infections related to the chondrodystrophy, he was readmitted at $\mathbf{1 0}$ months of age to the surgical unit for thoracic reconstruction.

Physical examination at this time disclosed a chronically ill, wasted infant weighing $5.8 \mathrm{~kg}$. The respirations were $80 /$ minute and the heart rate $152 /$ minute. The liver was palpable 6 to $7 \mathrm{~cm}$ below the right costal margin and the spleen was palpable about $3 \mathrm{~cm}$ below the left costal margin. Blood gases in room air had not significantly changed.

At surgery the sternum and manubrium were split longitudinally from the suprasternal notch to the xiphoid process. Separation of approximately 2.5 $\mathrm{cm}$ was maintained by a stainless steel bar sutured by wire in a horizontal plane at the level of the fourth rib (Fig. 1). The front of the pericardium and anterior mediastinum were protected by Marlex mesh.

The infant tolerated this surgical procedure but developed massive gastric bleeding 12 hours postoperatively from two antral stress ulcers. Conservative measures failed to control the bleeding and the ulcers had to be oversewn. Vagotomy and pyloroplasty were done as well. He was discharged after being in hospital for 25 days with blood gases $p \mathrm{H} \mathrm{7.39}, \mathrm{PCO}_{2} 35, \mathrm{Po}_{2} 62$, and a respiratory rate of $50 /$ minute. During the 5 months after operation he remained small and did not gain weight despite an excellent appetite, improved ventilatory function, reduction in respiratory rate, and elimination of respiratory infections.

At 15 months he was readmitted for evaluation of chronic diarrhoea. At this time he was having 6 to 7 large, watery, foul-smelling bowel movements a day. His abdomen was protuberant, the liver was about 4 cm below the right costal margin, and there was no splenomegaly. The remainder of the examination, except for the reconstructed chest cage and inanition, was unremarkable. $\mathrm{Hb}$ was $12.1 \mathrm{~g} / 100 \mathrm{ml}$, haematocrit $35 \cdot 2$, platelets 373,000 , reticulocyte count $4 \cdot 0 \%$, WBC 7100 with $6 \%$ polymorphs, $89 \%$ lymphocytes, and $3 \%$ monocytes. Serum immunoelectrophoresis was normal. Stool cultures were negative for salmonella and shigella and no ova or parasites were found. Sweat sodium was $19 \mathrm{mEq} / \mathrm{l}$. and sweat chloride 23 $\mathrm{mEq} / \mathrm{l}$. Chest $x$-rays showed a significant improvement of the anteroposterior diameter with clear lung markings. The bone age was that of a 1-year-old. On a regular diet stool fat excretion was $21 \mathrm{~g} / 24 \mathrm{~h}$ and 
stool trypsin content was $2.0 \mu \mathrm{g} / \mathrm{g}$ stool (normal $80-740 \mu \mathrm{g} / \mathrm{g}$ stool). An upper gastrointestinal series was normal. Duodenal intubation for pancreatic enzyme studies, and small bowel biopsy were performed. At this time the bar was removed from the chest, with stabilization of the chest circumference.

Gastrointestinal studies. A Rawson Abbott gastroduodenal tube, modified for infants, was passed under fluoroscopic control into the second portion of the duodenum. The gastric and duodenal juices were collected separately on ice and under mineral oil. Duodenal basal collection for 50 minutes was followed by 2 units secretin (obtained from GIH Karolinska Institute, Sweden) per kg of body weight intravenously within 2 minutes and collection continued for another 50 minutes. Trypsin, chymotrypsin, lipase, and amylase were measured by methods previously decribed (Caraway, 1959; Cherry and Crandall, 1932; Haverback et al., 1963).

On two separate occasions the pancreatic secretory volume and bicarbonate response to intravenous secretin was adequate and similar to values reported by others in infants of the same age (Hadorn et al., 1968). However, lipase, amylase, and trypsin activities in both basal and stimulated conditions were low or undetectable (see Table). Chymotrypsin activity could not be

\section{TABLE}

Concentrations of pancreatic enzymes and enterokinase in duodenal juice

\begin{tabular}{|c|c|c|c|c|}
\hline \multirow{2}{*}{$\begin{array}{c}\text { Age } \\
\text { (mth) }\end{array}$} & \multicolumn{2}{|c|}{15} & \multicolumn{2}{|c|}{21} \\
\hline & Basal & $\begin{array}{l}\text { Post- } \\
\text { secretin }\end{array}$ & Basal & $\begin{array}{c}\text { Post- } \\
\text { secretin }\end{array}$ \\
\hline $\begin{array}{l}\text { Colour } \\
\text { pH } \\
\text { Volume }(\mathrm{ml} / \mathrm{kg} \text { per } 50 \mathrm{~min}) \\
\text { Bicarbonate (Meg } / \mathrm{kg} \\
\quad \text { per } 50 \mathrm{~min}) \\
\text { Lipase }(\mathrm{IU} / \mathrm{kg} \text { per } 50 \mathrm{~min}) \\
\text { Amylase }(\mathrm{IU} / \mathrm{kg} \text { per } 50 \mathrm{~min}) \\
\text { Trypsin }(\mu \mathrm{g} / \mathrm{ml}) \\
\text { Chymotrypsin }(\mu \mathrm{g} / \mathrm{ml}) \\
\text { Enterokinase }(\mathrm{EKU} / \mathrm{ml})\end{array}$ & $\begin{array}{l}\text { Yellow } \\
7 \cdot 4 \\
0 \cdot 537 \\
0 \cdot 009 \\
1 \cdot 24 \\
4 \cdot 45 \\
2 \cdot 0 \\
0 \cdot 0 \\
\text { ND }\end{array}$ & $\begin{array}{l}\text { Yellow } \\
7 \cdot 76 \\
4 \cdot 60 \\
0 \cdot 18 \\
1 \cdot 40 \\
0 \cdot 34 \\
2 \cdot 0 \\
0 \cdot 0 \\
N D \star\end{array}$ & $\begin{array}{l}\text { Yellow } \\
6 \cdot 4 \\
1 \cdot 40 \\
0 \cdot 003 \\
1 \cdot 0 \\
0 \cdot 24 \\
0 \cdot 0 \\
0 \cdot 0 \\
1 \cdot 2\end{array}$ & $\begin{array}{l}0 \cdot 205 \\
0 \cdot 0 \\
0 \cdot 0 \\
0 \cdot 0 \\
0 \cdot 0 \\
1 \cdot 2\end{array}$ \\
\hline
\end{tabular}

$\star$ Not determined.

EKU, amount of enzyme converting $1 \mu \mathrm{g}$ trypsinogen to trypsin/ min (Hadorn et al.).

detected in specimens from either test, even after the addition of known amounts of trypsin in an attempt to activate chymotrypsinogen. The addition of enterokinase did not increase trypsin or chymotrypsin activity. These results indicate a diminution of pancreatic acinar rather than ductal secretory response.

The mucosal structure of a duodenal biopsy obtained with a suction biopsy tube (Quinton Instrument Co.) fluoroscopically, placed in the third portion of the duodenum, was normal.

Case 2. A younger brother, age 4 months, was born with a milder degree of the congenital chest abnormality and has remained free of pulmonary problems. His growth and development are normal. He has no gastrointestinal problems and has a normal amount of trypsin in the stool.

\section{Discussion}

A family in which two male sibs were affected with asphyxiating thoracic dystrophy has been studied. In the older sib the restrictive thoracic problem was sufficient to cause severe respiratory embarrassment and required surgical intervention to increase the volume of the thoracic cavity. Previous surgical procedures designed to enlarge the thoracic volume by resecting the costochondrial junctions were unsuccessful (Durand et al., 1965). We followed a similar surgical approach to the one reported by Barnes et al. (1971) in which the sternum was split and the thoracic cage fixed in an expanded position by a horizontal strut, thus increasing the thoracic circumference.

After the successful operation he still did not grow and diarrhoea became a significant clinical problem (Fig. 2). The presence of a neutropenia

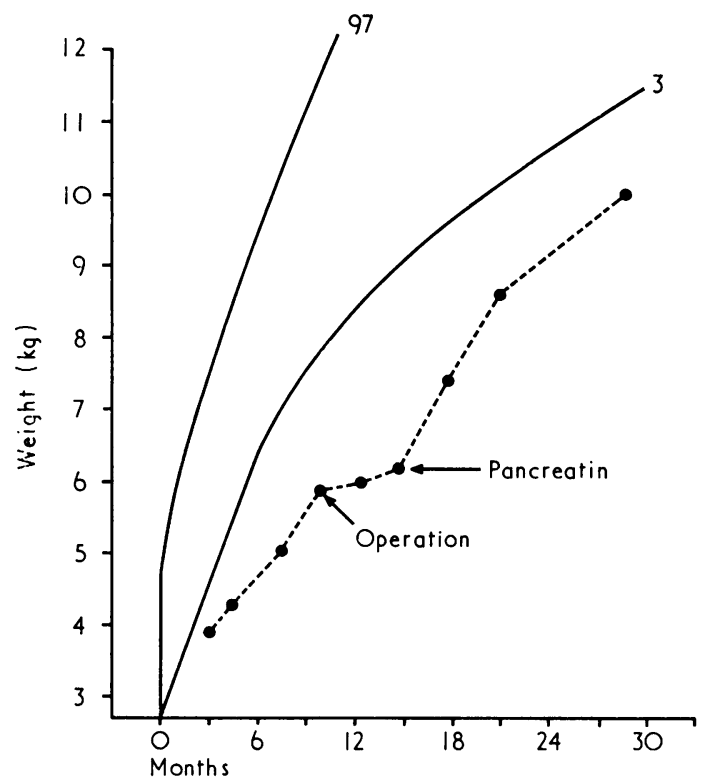

FIG. 2.-Growth curve showing increase in weight gain after treatment with pancreatic supplementation.

suggested that pancreatic disease was responsible for the increased faecal fat and failure to thrive (Burke et al., 1967; Shmerling et al., 1969; Shwachman et al., 1964). The results of the two pancreatic 
function studies using intravenous secretin suggest that the ductular elements were functioning normally but that the acinar component of secretin was impaired. Though we did not use pancreozymin to stimulate zymogen secretion, the marked diminution of hydrolytic activity towards polysaccharides, triglycerides, and proteins is extremely unusual. Sweat chlorides performed on several occasions were normal, thus it is unlikely that cystic fibrosis was the cause of the pancreatic insufficiency. The findings of normal levels of enterokinase activity in duodenal aspirates eliminates the possibility of an enterokinase deficiency (Hadorn et al., 1969; Haworth et al., 1971; Herdman and Langer, 1968; and Tarlow et al., 1970). Neither can we suggest the diagnosis of trypsinogen deficiency since addition of small amounts of trypsin to the pancreatic secretions did not further activate the conversion of chymotrypsinogen to chymotrypsin (Morris and Fisher, 1967; Townes, 1965; Townes, Bryson, and Miller, 1967). Though the effect of vagotomy on pancreatic function has not been studied in children, vagotomy in adults is not associated with a decreased pancreatic response to secretin (Dreiling, Druckerman, and Hollander, 1952). Our patient, with his neutropenia and impaired pancreatic function after secretin stimulation, is similar to those originally described by Shwachman et al., 1964. While there is no clear explanation for the association of pancreatic insufficiency and bone marrow dysfunction there is a pathological explanation for the exocrine pancreatic insufficiency in Shwachman's syndrome in that the acinar cells of the pancreas are replaced by adipose tissue.

There has been one other report of a patient with diarrhoea associated with asphyxiating thoracic dystrophy (Durand et al., 1965). This child died three weeks after an attempted thoracic correction and the aetiology of the chronic diarrhoea was never determined.

Pancreatic supplementation given at each meal has improved the steatorrhoea and enabled the older infant to resume growth at his predicted rate (Fig. 2). Stool fat analysis 2 months after treatment showed a reduction from 21 to $10 \mathrm{~g} / 24 \mathrm{hr}$. This correction of the retarded growth was made 6 months after the operation and after pancreatic supplementation. It is doubtful that the chronic respiratory insufficiency was the major cause for this boy's failure to thrive.
The author thanks Mr. Howard Earle for his laboratory assistance.

\section{REFBRENCES}

Barnes, N. D., Hull, D., Milner, A. D., and Waterston, D. J. (1971). Chest reconstruction in thoracic dystrophy. Archives of "1. Disease in Childhood, 46, 833.

Barnes, N. D., Hull, D., and Symons, J. S. (1969). Thoracic dystrophy. Archives of Disease in Childhood, 44, 11.

Burke, V., Colebatch, J. H., Anderson, C. M., and Simons, M. J. (1967). Association of pancreatic insufficiency and chronic neutropenia in childhood. Archives of Disease in Childhood, 42, 147.

Caraway, W. T. (1959). A stable starch substrate for the determination of amylase in serum and other body fluids. American Fournal of Clinical Pathology, 32, 97.

Cherry, I. S., and Crandall, L. A., Jr. (1932). The specificity of pancreatic lipase: its appearance in the blood after pancreatic injury. American fournal of Physiology, 100, 266.

Durand, P., Razzi, A., Mastragostino, S., and Gimelli, F. A. (1965). La distrofia toracica asfissiante (malattia di Jeune): tentativo d'intervento chirurgico sulla gabbia toracica. Minerva Pediatrica, 17, 1437.

Dreiling, D. A., Druckerman, L. J., and Hollander, F. (1952). The effect of complete vagisection and vagal stimulation on pancreatic secretion in man. Gastroenterology, 20, 578.

Hadorn, B., Tarlow, M. J., Lloyd, J. K., and Wolff, O. H. (1969). Intestinal enterokinase deficiency. Lancet, 1, 812.

Hadorn, B., Zoppi, G., Shmerling, D. H., Prader, A., McIntyre, I., and Anderson, C. M. (1968). Quantitative assessment of exocrine pancreatic function in infants and children. Fournal of Pediatrics, 73, 39.

Hanissian, A. S., Riggs, W. W., and Thomas, D. A. (1967). Infantile thoracic dystrophy-a variant of Ellis-Van Creveld syndrome. Fournal of Pediatrics, 71, 855.

Haverback, B. J., Dyce, B. J., Gutentag, P. J., and Montgomery, D. W. (1963). Measurement of trypsin and chymotrypsin in stool. Gastroenterology, 44, 588 .

Haworth, J. C., Gourley, B., Hadorn, B., and Sumida, C. (1971) Malabsorption and growth failure due to intestinal enterokinase deficiency. Fournal of Pediatrics, 78, 481.

Herdman, R. C., and Langer, L. O. (1968). The thoracic asphyxiant dystrophy and renal disease. American fournal of Diseases of Children, 116, 192.

Jeune, M., Beraud, C., and Carron, R. (1955). Dystrophie thoracique asphyxiante de caractère familial. Archives Francaises de Pédiatrie, 12, 886.

Morris, M. D., and Fisher, D. A. (1967). Trypsinogen deficiency disease. American Fournal of Diseases of Children, 114, 203.

Pirnar, T., and Neuhauser, E. B. D. (1966). Asphyxiating thoracic dystrophy of the newborn. American fournal of Roentgenology, 98, 358 .

Shmerling, D. H., Prader, A., Hitzig, W. H., Giedion, A., Hadorn, Z. B., and Kuhni, M. (1969). The syndrome of exocrine pancreatic insufficiency, neutropenia, metaphyseal dysostosis and dwarfism. Helvetica Paediatrica Acta, 24, 547.

Shwachman, H., Diamond, L. K., Oski, F. A., and Khaw, K.-T. (1964). The syndrome of pancreatic insufficiency and bone marrow dysfunction. Fournal of Pediatrics, 65, 645.

Tarlow, M. J., Hadorn, B., Arthurton, M. W., and Lloyd, J. K. (1970). Intestinal enterokinase deficiency. Archives of Disease in Childhood, 45, 651.

Townes, P. L. (1965). Trypsinogen deficiency disease. Fournal of Pediatrics, 66, 275.

Townes, P. L., Bryson, M. F., and Miller, G. (1967). Further observations on trypsinogen deficiency disease: Report of a second case. Fournal of Pediatrics, 71, 220.

Correspondence to Dr. Karjoo, Division of Gastroenterology, The Children's Hospital of Philadelphia, 1740 Bainbridge Street, Philadelphia, Pa. 19146, U.S.A. 